\title{
Molecular Simulations of Swelling Clay Minerals
}

\author{
Tim J. Tambach,* Emiel J. M. Hensen," and Berend Smit \\ Department of Chemical Engineering, University of Amsterdam, Nieuwe Achtergracht 166, \\ 1018 WV Amsterdam, The Netherlands
}

Received: January 14, 2004; In Final Form: March 15, 2004

\begin{abstract}
We have carried out molecular simulations in the grand-canonical ensemble of water and cations in Wyoming and Arizona montmorillonite clay minerals, with varying relative humidity. Several water models and cations are used to investigate the swelling of these clays. We show how the water content depends on the type of clay, type of cation, the basal spacing, and the relative humidity. Related to the layering of water molecules in the interlayer space, the pressure normal to the clay sheets oscillates as a function of the basal spacing. Minima in corresponding free energy curves indicate the presence of dehydrated states and layered hydrates. The development of these stable states and the corresponding basal spacings are in agreement with experimental data. Density profiles show significantly different interlayer structures depending on the type of clay and models used. We show a relation between formation of two-layer hydrates and the position of the cations. The simulations with the MCY water model underestimate the spacings of two- and three-layer hydrates, whereas our simulations with the TIP4P model produce a better agreement. Therefore, we recommend the TIP4P model for simulating clay minerals. In addition, we report remarkable ordering of cations and water molecules in a one-layer Arizona montmorillonite hydrate.
\end{abstract}

\section{Introduction}

Clay minerals have a wide range of properties, which make them important to the Earth sciences, engineering, and industry. ${ }^{1}$ These minerals can serve as ion exchangers or catalyze reactions, ${ }^{2}$ but in other fields their swelling properties are unwanted. Environmental regulations require that oil exploration industries use water-based drilling fluids, instead of oil-based ones. ${ }^{3}$ As a consequence, an excess of water may cause serious problems when drilling through geological formations containing a high weight-percentage of swelling clay minerals. In the worst case, the well bore may even collapse. ${ }^{4}$ Therefore, fundamental knowledge of swelling clay minerals is of great importance to fully understand their behavior and to handle their properties efficiently.

Swelling clay minerals have been studied for a long time. They consist of negatively charged sheets due to isomorphic substitution. In the interlayer space of the clay mineral, water molecules hydrate charge-compensating cations (counterions). Experimentally, this hydration is studied for different types of clays under varying experimental conditions, ${ }^{5-14}$ for example, by measuring the basal spacings (using X-ray powder diffraction) as a function of the relative humidity. The type of clay and charge-compensating cations are other important aspects determining the basal spacing. Increasing relative humidity raises the water content, which may lead to swelling. It is accepted that swelling occurs through distinct steps forming one-, two-, and three-layer hydrates. ${ }^{10}$

Natural clay samples usually contain structural and chemical heterogeneities, which make the interpretation of the experimental data more difficult. Molecular simulation is an important tool to overcome these problems and do systematic research

* Corresponding author. E-mail: tambach@science.uva.nl.

\# Present address: Schuit Institute of Catalysis, Eindhoven University of Technology, P.O. Box 513, 5600 MB Eindhoven, The Netherlands. on swelling clay minerals. Many computational studies dealing with water and cations in swelling clays, in particular montmorillonite, have appeared in the literature. ${ }^{3,15-36,42,46}$ In these studies, a couple of techniques were used. A number of authors carried out simulations in the $\mathrm{NP}_{z} \mathrm{~T}$ ensemble. ${ }^{15-19,22-25,28,31-36,42,46}$ This technique imposes the pressure normal to the clay layers $\left(P_{z}\right)$ and allows the basal spacing $(d 001)$ to equilibrate at a given number of water molecules. An alternative approach is simulating swelling clay minerals in the grand-canonical $(\mu \mathrm{VT})$ ensemble..$^{3,18-21,26-28}$ In this case, water molecules are inserted into or removed from the clay system under the condition of a fixed water chemical potential, which is related to the water vapor pressure. Hensen and $\mathrm{Smit}^{29}$ combined the $\mathrm{NP}_{z} \mathrm{~T}$ and the $\mu \mathrm{VT}$ approach and carried out simulations in the $\mu \mathrm{P}_{z} \mathrm{~T}$ ensemble. Recently, ab initio molecular dynamics calculations have appeared in the literature as well. ${ }^{30}$

Simulation studies of the clay-cation-water system are done with a number of different interaction potentials. This makes it difficult to obtain systematic insights in, for example, the effects of cations or humidity on the swelling. The use of certain potentials usually starts with the choice for a particular water model. Three types of water model are commonly used for simulating swelling clay minerals: MCY, 3,17,20,22-25,34-36,46 TIP4P, ${ }^{15,16,18,19,26-29,42}$ and SPC/E. ${ }^{21,31-33}$ There is no consensus in the literature on, for example, which interaction potential to choose for hydrated clays. ${ }^{30}$

Several types of clay are investigated ${ }^{18}$ in the $\mu \mathrm{VT}$ ensemble, as well as different types of cations. These simulations are all carried out at one particular value of the water chemical potential and varying basal spacing. Delville and Sokolowski ${ }^{28}$ performed simulations as a function of the water chemical potential and at a fixed basal spacing. Other studies were focused on the wetting properties of a clay surface as a function of the water chemical potential. ${ }^{27,28}$ In a previous study, ${ }^{20}$ we showed adsorption isotherms of water in $\mathrm{Li}-, \mathrm{Na}-$, and $\mathrm{K}$-montmorillonite 

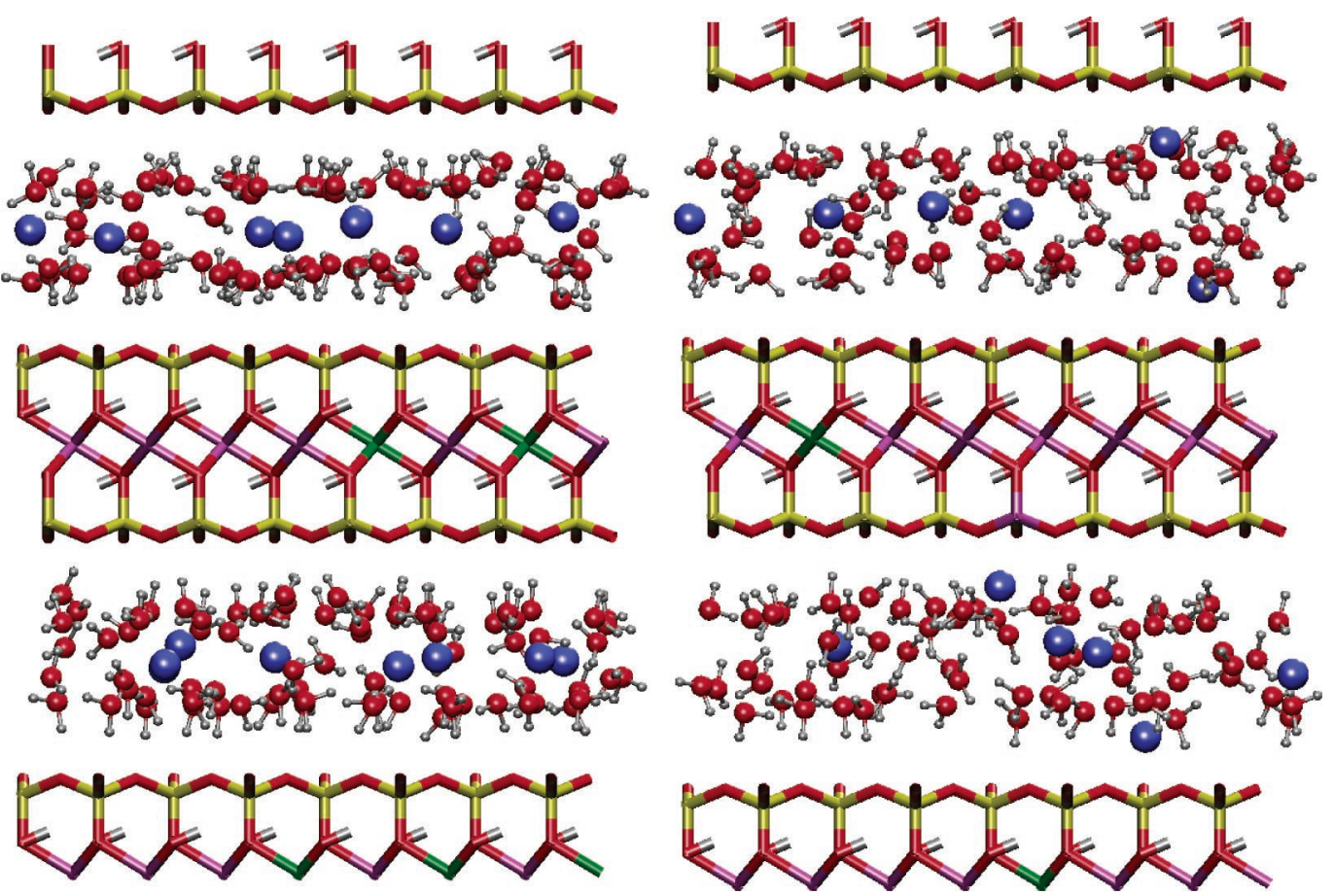

Figure 1. Snapshot of Arizona (left) and Wyoming (right) Na-montmorillonite at a relative humidity of $67 \%$ using the TIP4P model. These stable two-layer hydrates at 15.00 and $15.50 \AA$, respectively, correspond to the density profiles shown in Figure 7 . The tubes represent the clay structure and the spheres the water molecules and cations. In the clay, $\mathrm{O}=$ red, $\mathrm{H}=$ silver, $\mathrm{Si}=$ yellow, $\mathrm{Al}=$ purple, and $\mathrm{Mg}=$ green. For water, $\mathrm{O}=$ red and $\mathrm{H}=$ silver, and cation $\mathrm{Na}=$ blue

at fixed basal spacing $(12.0 \AA)$ within a range of water chemical potentials.

In this work, we extend these studies by performing $\mu \mathrm{VT}$ calculations in the intracrystalline swelling domain (i.e., basal spacing $<20 \AA)$. We carry out a systematic variation of the relative humidity (from $0 \%$ to $>100 \%$ ) and the basal spacing (from 9.0 to $20 \AA$ ). With this approach we want to gain more insight into the stability of swelling states as a function of the experimental relative humidity. We use our methodology to study Wyoming and Arizona Na-montmorillonite with the TIP4P water model and Arizona Li-, Na-, and K-montmorillonite with the MCY water model. With respect to the two different water models, we investigate the sensitivity on the swelling.

\section{Methodology}

II.A. Clay Model and Potential Parameters. We simulated Wyoming and Arizona Na-montmorillonite with a TIP4P-based model and Arizona Li-, Na- and, K-montmorillonite with a MCY-based model. Wyoming montmorillonite carries isomorphic substitutions in both its octahedral and tetrahedral layers, with the structural formula $\mathrm{M}_{0.75}\left[\mathrm{Si}_{7.75} \mathrm{Al}_{0.25}\right]\left[\mathrm{Al}_{3.5} \mathrm{Mg}_{0.5}\right] \mathrm{O}_{20}(\mathrm{OH})_{4}$, where " $\mathrm{M}$ " represents a monovalent counterion. Arizona montmorillonite only bears substitutions in the octahedral sheet with the structural formula $\mathrm{M}_{1.00}\left[\mathrm{Si}_{8}\right]\left[\mathrm{Al}_{3} \mathrm{Mg}\right] \mathrm{O}_{20}(\mathrm{OH})_{4}$. We used the clay model, describing atomic clay coordinates and partial charges, developed by Skipper et al. ${ }^{22}$ In addition to the Coulombic interactions, the TIP4P-based interactions in the clay-cation-water system are described by the van der Waals potentials taken from Chávez-Páez et al. ${ }^{19}$ and Boek et al. ${ }^{15}$ We took MCY-based van der Waals interactions from the work of Park and Sposito. ${ }^{36}$

The simulation cell consisted of eight montmorillonite unitcells making up a clay patch of $21.12 \AA$ ( $x$-dimension) by 18.28 $\AA$ ( $y$-dimension). The thickness of one clay layer was $6.56 \AA$. We applied three-dimensional periodic boundary conditions with a cutoff radius $\left(r_{\text {cut }}\right)$ of $9.14 \AA$. As the minimum basal spacing of these types of clays is approximately $9.25 \AA$, duplication of the simulation cell in the $z$-direction was necessary in order to avoid problems in the nearest-image convention for short-range interactions. Chávez-Páez et al. ${ }^{19}$ proved that this is necessary for clay systems bearing small spacings. Typical snapshots of the simulated systems are shown in Figure 1. Due to the duplication, the total system consisted of 16 montmorillonite unit-cells with a total weight of $11487 \mathrm{amu}$ (Arizona) and $11504 \mathrm{amu}$ (Wyoming). The mass of the counterions should be added to obtain the total dry clay weight.

We carried out isomorphic substitution randomly, by replacing one $\mathrm{Al}^{3+}$ atom by one $\mathrm{Mg}^{2+}$ atom in each unit-cell. We obeyed Loewenstein's rule, which states that the locations of two substitution sites are not adjacent to each other. Previous work ${ }^{19}$ shows a minor effect of specific substitutions in the tetrahedral sheet on montmorillonite swelling. Despite this observation, we chose random substitution sites only once for both clay types and used these crystal structures for all simulations. To compensate the resulting net charge, we added eight monovalent counterions $\left(\mathrm{M}^{+}\right)$to each interlayer space of the Arizona clay minerals and six counterions for Wyomingtype clay. We investigated all clays with varying water chemical potential, related to the relative humidity (see section II.C.).

II.B. Simulation Details. We used a combination of molecular dynamics and Monte Carlo techniques to simulate water molecules and counterions in rigid montmorillonite in the $\mu \mathrm{VT}$ ensemble. Molecular dynamics was applied to displace the cations and water molecules, and a special adaptation of the Monte Carlo technique was used to insert or remove water molecules from the interlayer space of the clay. ${ }^{20}$ Insertions of molecules in dense systems can be biased in order to improve the probability of acceptance. ${ }^{37}$ In a recent paper ${ }^{20}$ we showed that, in comparison with conventional techniques, the configurational biased Monte Carlo (CBMC) technique makes simulations up to higher densities possible. For particle movement we 
apply the SHAKE algorithm to maintain the rigidity of the water molecules. We calculated long-range Coulombic interactions by using the Ewald summation method with a reciprocal space cutoff $(k \geq 6 \AA)$ and $\alpha=0.35$. We kept all clay atoms frozen during the simulation.

All simulations were performed at $T=298 \mathrm{~K}$ and a timestep $(t)$ of 1.0 fs. Each simulation started with a 10 ps equilibration using the Evans thermostat. After temperature equilibration, we applied the Nosé-Hoover thermostat and carried out 150 ps particle equilibration, followed by 200 ps to gather statistical data. Resulting averages include the pressure normal to the clay sheets $\left(P_{z}\right)$, the number of water molecules, and the positions of cations and water molecules. We carried out the calculation of $P_{z}$ by using the trial volume change method. ${ }^{37}$ Every 100 time-steps (on average), we virtually displaced (scaled) all molecules normal to the clay sheets within the range of $-\Delta z_{\max }<\Delta z<\Delta z_{\max }$, with $\Delta z_{\max }=0.001 \AA$. By calculating the difference in potential energy $\left(\Delta U_{\text {pot }}\right)$, the formula for calculating $P_{z}$ is

$$
P_{z}=\frac{\left(N_{\text {water }}+N_{\text {cation }}\right) k_{\mathrm{b}} T}{V}-\frac{\Delta U_{\text {pot }}}{x y \Delta z}
$$

where $N_{\text {water }}$ is the number of water molecules, $N_{\text {cation }}$ the number of cations, $k_{\mathrm{b}}$ the Boltzmann constant, $T$ the temperature, and $x$ and $y$ the corresponding dimensions of the clay system. In eq 1 we use a molecular approach to calculate $P_{z}$, which implies that we must scale the center of mass of the water molecules and clay layers. We obtained the free energy $(\Delta F)$ by integrating $P_{z}$ as a function of the basal spacing $\left(s_{z}\right)$, using the following formula $^{21}$

$$
\Delta F=-A \int_{s_{z}^{0}}^{s_{z}}\left(P_{z}\left(s_{z}^{\prime}\right)-P_{\text {ext }}\right) \mathrm{d} s_{z}^{\prime}
$$

where $A$ is the area of the clay sheets $\left(18.28 \times 21.12 \AA^{2}\right), s_{z}^{0}$ the reference basal spacing (arbitrarily chosen), and $P_{\text {ext }}$ the external pressure. The latter variable does not depend on our simulations but becomes important at burial depths in the Earth's crust, where elevated pressures occur.

We carried out simulations with varying chemical potential, related to the relative humidity (see below). In addition to our $\mu$ VT simulations, we carried out NVT simulations of dry clay to simulate the dehydrated state. NVT simulations would be similar to $\mu \mathrm{VT}$ simulations with an infinitely low water chemical potential. However, it would be useless to spend CPU time attempting to insert water molecules, which will be accepted with an infinitely small probability.

II.C. Thermodynamics of Water Models. The ab initio based MCY water model ${ }^{38}$ was designed for describing the interaction between two water molecules. As a consequence, the thermodynamic properties of water are not very well described with this model, in contrast to the TIP4P water model $^{39}$ based on experimental data. This discrepancy is also illustrated in Figure 2, in which we compare the equations of state of the MCY and TIP4P model with experimental data.

In our simulations we apply a water chemical potential $\left(\mu_{\text {water }}\right)$ to insert or remove water molecules from clay minerals. Swelling clay experiments can be carried out in bulk water, but the swelling process is usually studied with a mixture of air and water vapor. In such a mixture, the relative humidity $(\mathrm{RH})$ is given by

$$
\mathrm{RH}=\left(P_{\text {water }} / P_{\text {water }}^{\mathrm{sat}}\right) \times 100 \%
$$

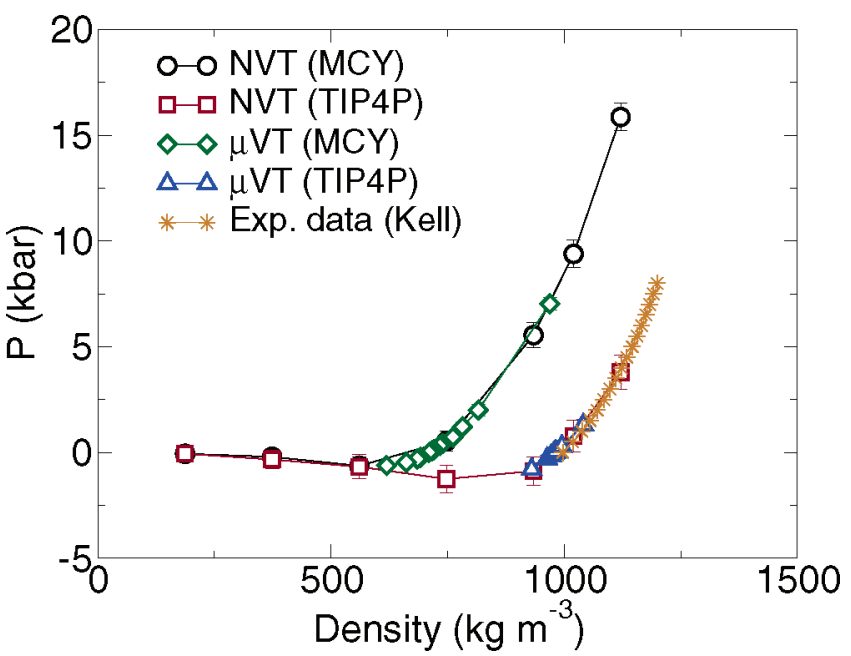

Figure 2. Equation of state of the TIP4P and MCY model, calculated with NVT and $\mu \mathrm{VT}$ simulations. We simulated a cubic box $(r=20.0$ $\AA$ ) of water molecules at $T=298 \mathrm{~K}$ and obtained the experimental data from Kell. ${ }^{47}$

where $P_{\text {water }}$ is the partial pressure of water vapor and $P_{\text {water }}^{\text {sat }}$ the saturated water vapor pressure. At saturation, the relative water vapor pressure $\left(P_{\text {water }} / P_{\text {water }}^{\text {sat }}\right)$ is equal to 1.0 and the relative humidity is $100 \%$. To allow a direct comparison between the present computer simulations and experimental data, we have to convert a water chemical potential into a partial pressure of water. The water chemical potential is directly related to the fugacity of water $\left(f_{\text {water }}\right)$

$$
\frac{f_{\text {water }}}{f_{\text {water }}^{\text {sat }}}=\mathrm{e}^{-\left(\mu_{\text {water }}^{\text {sat }}-\mu_{\text {water }}\right) / R T}
$$

where $\mu_{\text {water }}^{\text {sat }}$ and $f_{\text {water }}^{\text {sat }}$ are equal to the water chemical potential and fugacity when the air is saturated with water vapor. To convert the relative water fugacity to the relative water vapor pressure, we use the fugacity coefficient $(\phi)$

$$
\phi(P)=\frac{f}{P}
$$

giving

$$
\frac{P_{\text {water }}}{P_{\text {water }}^{\text {sat }}}=\frac{f_{\text {water }} / \phi\left(P_{\text {water }}\right)}{f_{\text {water }}^{\text {sat }} / \phi\left(P_{\text {water }}^{\text {sat }}\right)}
$$

where $\phi\left(P_{\text {water }}\right)$ and $\phi\left(P_{\text {water }}^{\text {sat }}\right)$ are the fugacity coefficients at the given partial pressure and at saturated partial vapor pressures of water, respectively.

To determine these coefficients, we consider an experimental system of liquid water with a vapor phase containing air and water. If we assume that air behaves like an ideal gas mixture and does not influence the liquid phase, we can compute the fugacity coefficients from the equation of state of pure water. In that case, we assume that the pressure and chemical potential of pure water are equal to the partial pressure and chemical potential in the air-water system. In addition, we used the Peng-Robinson equation of state and the saturated water vapor pressure of water at $298 \mathrm{~K}$ to calculate the fugacity coefficients. ${ }^{40}$ Exactly at the coexistence point, the fugacity coefficient $\phi\left(P_{\text {water }}^{\text {sat }}\right)$ is 0.817 . If we substitute this value and eq 4 into eq 6 , and substitute the latter equation into eq 3 , we obtain the following equation: 
TABLE 1: Relative Water Fugacity $\left(f_{\text {water }} / f_{\text {water }}^{\text {sat }}\right)$, Relative Water Vapor Pressure $\left(\boldsymbol{P}_{\text {water }} / \boldsymbol{P}_{\text {water }}^{\text {sat }}\right)$, and Relative Humidity (RH) Corresponding to the Water Chemical Potential for the TIP4P and MCY Water Model

\begin{tabular}{lllll}
\hline & $\begin{array}{c}\mu_{\text {water }} \\
\left(\mathrm{kJ} \mathrm{mol}^{-1}\right)\end{array}$ & $\begin{array}{c}f_{\text {water }} / f_{\text {water }}^{\text {sat }} \\
(-)\end{array}$ & $\begin{array}{c}P_{\text {water }} / P_{\text {water }}^{\text {sat }} \\
(-)\end{array}$ & $\begin{array}{l}\text { RH } \\
(\%)\end{array}$ \\
\hline TIP4P $^{a}$ & -60.0 & $1.9 \times 10^{-3}$ & $1.6 \times 10^{-3}$ & 0.16 \\
& -50.0 & 0.11 & 0.089 & 8.9 \\
& -45.0 & 0.82 & 0.67 & 67 \\
MCY $^{b}$ & -43.4 & na & na & $>100$ \\
& -50.0 & 0.018 & 0.014 & 1.4 \\
& -41.7 & 0.50 & 0.41 & 41 \\
& -40.0 & 1.0 & 1.0 & 100
\end{tabular}

${ }^{a}$ The saturated water chemical potential corresponds to $-44.5 \mathrm{~kJ}$ $\mathrm{mol}^{-1} .{ }^{b}$ The saturated water chemical potential corresponds to -40.0 $\mathrm{kJ} \mathrm{mol}^{-1}$

$$
\mathrm{RH}=\frac{81.7}{\phi\left(P_{\text {water }}\right)} \mathrm{e}^{-\left(\mu_{\text {water }}^{\mathrm{sat}}-\mu_{\text {water }}\right) / R T}
$$

Experimentally, the chemical potential of liquid water $\left(\mu_{\text {water }}^{\text {liquid }}\right)$ and $\mu_{\text {water }}^{\text {sat }}$ are approximately $-42.9 \mathrm{~kJ} \mathrm{~mol}^{-1}$. For the TIP4P model, we computed a value of $-44.5 \mathrm{~kJ} \mathrm{~mol}^{-1}$ for $\mu_{\text {water }}^{\text {liquid }}$, which is close to the value of $-43.4 \mathrm{~kJ} \mathrm{~mol}^{-1}$ by Chávez-Páez et al. ${ }^{19}$ For the MCY model, we computed a value of $-40.0 \mathrm{~kJ} \mathrm{~mol}^{-1}$. Since the saturated water chemical potential of the TIP4P and the MCY water models are different from each other, we cannot use the absolute chemical potential to compare our simulation results. Instead, we have to the use the relative water vapor pressure or the relative humidity. The water chemical potentials of the TIP4P and the MCY model, the corresponding relative water fugacities, the relative water vapor pressures, and the relative humidities are collected in Table 1. In the following we will use the relative humidity to facilitate a comparison with the experimental data.

\section{Results and Discussion}

III.A. Wyoming and Arizona Na-Montmorillonite with TIP4P Water. III.A.1. Water Adsorption Isotherms. Figure 3 displays the water content in Wyoming Na-montmorillonite, as a function of the basal spacing and for various values of the relative humidity. For sufficiently high relative humidity $(\mathrm{RH})$, the water content increases monotonically with increasing basal spacing. For a low RH, the water adsorption isotherm has a maximum value of $0.07 \mathrm{~g} / \mathrm{g}_{\text {clay }}$ close to a basal spacing of 15.0 $\AA$ for $\mathrm{RH}=0.16 \%$. With increasing spacing, the water content decreases to a constant value of $0.06 \mathrm{~g} / \mathrm{g}_{\text {clay }}$ starting near 17.0 $\AA$. In case of $\mathrm{RH}=8.9 \%$, the water content has a maximum of $0.16 \mathrm{~g} / \mathrm{g}_{\text {clay }}$ near $16.0 \AA$. The maxima occur due to a combination of increasing spacing and a too low relative humidity. At small interlayer spacings the water molecules form a film, in contact with both clay layers, even at low relative humidity. With increasing spacing, the effect of the clay is not sufficient to stabilize the water network resulting in a decrease of the number of water molecules toward a constant value. These situations describe clay wetting, which is studied by others. ${ }^{27,28}$ If the relative humidity is sufficiently high (for example $\mathrm{RH}=67 \%$ ), the water molecule network persists up to a higher spacing, but we expect that this isotherm will go to a constant value as well. As a function of the basal spacing, we expect the occurrence of maxima followed by a constant water content for every relative humidity smaller than $100 \%$ (corresponding to bulk conditions). At similar water chemical potential, our calculated water adsorption isotherm is in agreement with Chávez-Páez et al. ${ }^{19}$ (see Figure 3).

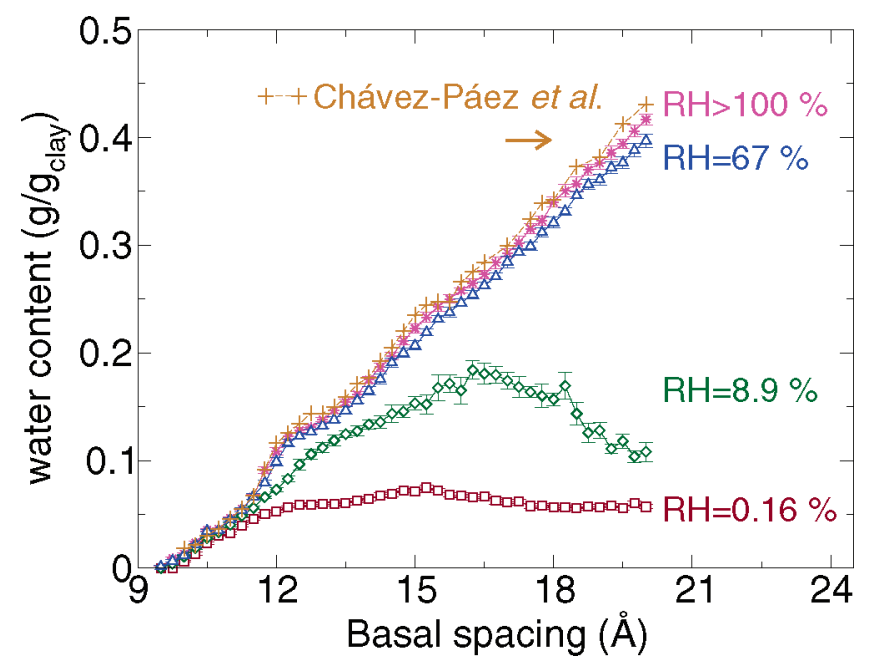

Figure 3. Water content as a function of the basal spacing for Wyoming Na-montmorillonite. Calculations are carried out using the TIP4P model for various values of the relative humidity (RH). The simulation data (upper curve) taken from Chávez-Páez et al. ${ }^{19}$ are calculated at the same water chemical potential $\left(\mu_{\text {water }}=-43.4 \mathrm{~kJ}\right.$ $\mathrm{mol}^{-1}$ ) as our simulated data at RH $>100 \%$.

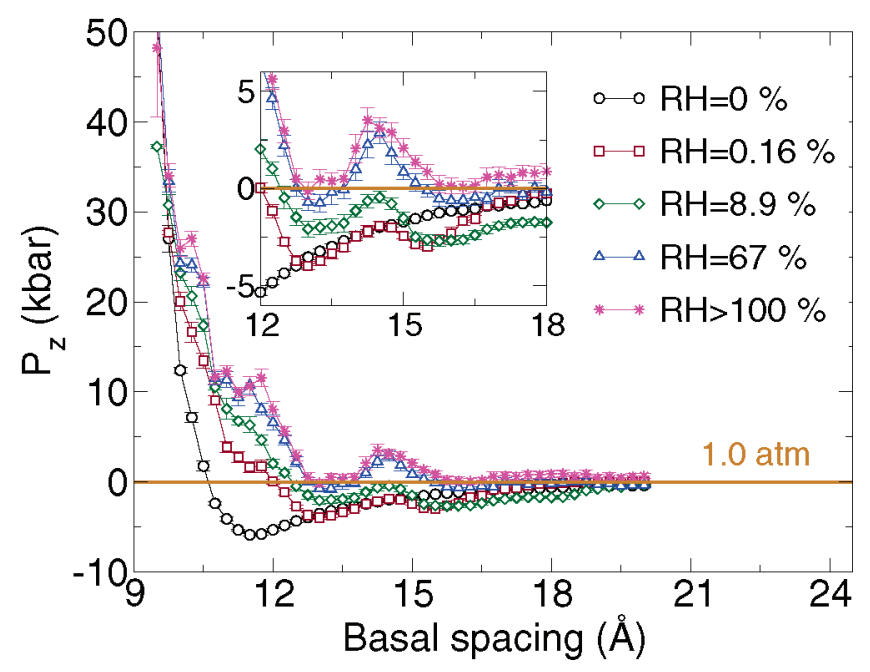

Figure 4. Pressure normal to the clay sheets $\left(P_{z}\right)$ as a function of the basal spacing for Wyoming Na-montmorillonite. Calculations are carried out using the TIP4P model for various values of the relative humidity (RH). We zoomed in on a particular area (see the inset).

The water contents in Arizona Na-montmorillonite show similar trends (not shown here), but are up to $10 \%$ higher compared with Wyoming Na-montmorillonite. For this type of clay and under the condition of $\mathrm{RH} \leq 8.9 \%$, the maxima of the isotherms are located at larger spacing and/or higher water content. We can explain the higher water content in Arizona Na-montmorillonite by the higher layer charge and the different distribution of the charges. The eight sodium cations in each interlayer space of Arizona montmorillonite are able to attract more water molecules than the six sodium ions in Wyoming montmorillonite. As a consequence, a network of water molecules is more stable in Arizona clay than in Wyoming clay under similar conditions. In addition, the cations in Wyoming montmorillonite have more affinity for the clay surface due to the substitution sites in the tetrahedral sheet (see below). This means that these cations will be less hydrated than the cations in Arizona montmorillonite, resulting in fewer water molecules in the interlayer space.

III.A.2. Pressure and Free Energy. Figure 4 shows the pressure normal to the clay sheets $\left(P_{z}\right)$ as a function of the basal 


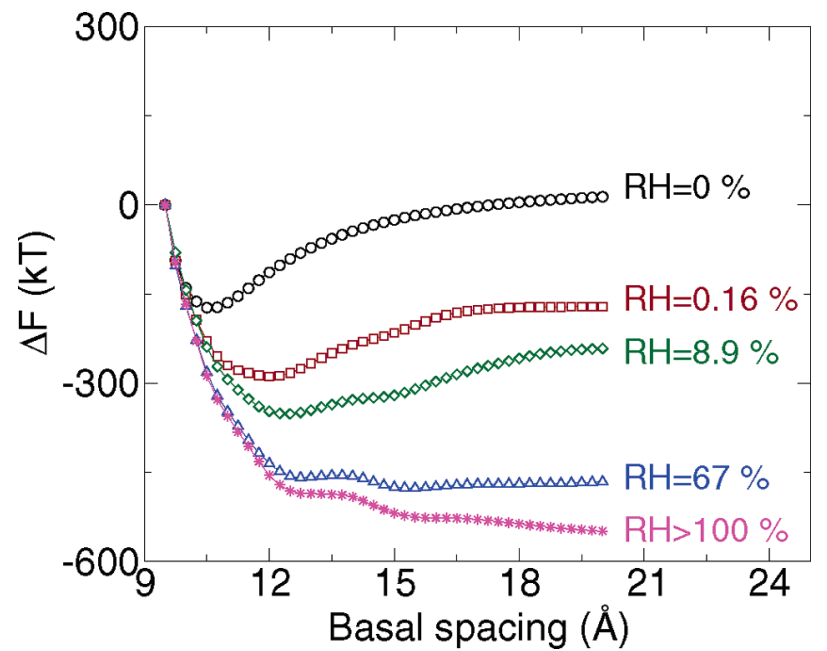

Figure 5. Free energy $(\Delta F)$ as a function of the basal spacing for Wyoming Na-montmorillonite. Calculations are carried out using the TIP4P model for various values of the relative humidity (RH). Note that we did not correct the data for an external pressure at $\mathrm{RH}>100 \%$.

spacing for Wyoming Na-montmorillonite at various values of the relative humidity. $P_{z}$ oscillates as a function of the basal spacing, which was already reported by others. ${ }^{3,18,19,21,41}$ These oscillations are related to the formation of one, two, or more water layers in the interlayer space. The clay system is stable when the internal pressure $P_{z}$ equals the external pressure outside the clay (usually atmospheric pressure). A lower pressure than the external pressure is interpreted as the tendency of the clay system to shrink until its internal pressure is equal to the external pressure. A higher pressure than the external one will induce swelling. The intersections of the pressure curves (with a negative slope; see below) with the external pressure allows the identification of stable states. ${ }^{19,21}$ If no pressure is applied, the external pressure will be equal to the atmospheric pressure. In addition, our simulations allow the investigation of the stable states at the elevated pressures in the burial depths of the Earth's crust. In that case we have to examine the intersections of the curves with such an elevated pressure. We should note that under these conditions, elevated temperatures are usually also the case, while our simulations are carried out at 298 K. De Siqueira et al. ${ }^{42}$ used elevated pressures and temperatures for their $\mathrm{NP}_{z} \mathrm{~T}$ simulations and found good agreement with experimental results.

We obtained the swelling free energy for Wyoming Namontmorillonite (see Figure 5) by integration of the pressure (Figure 4), according to eq 2. The swelling free energy of Arizona Na-montmorillonite is shown in Figure 6. To identify stable states we have to determine the minima of the free energy curves. At very low relative humidity $(\mathrm{RH}=0 \%)$ we simulate dehydrated states for both clay types with a basal spacing of $10.5 \AA$. We discuss the dehydrated state in more detail later (see III.A.4. Dehydrated States). When we increase the relative humidity to $0.16 \%$, we observe one-layer hydrates with basal spacings slightly lower (Arizona) and higher (Wyoming) than $12.0 \AA$. In addition, we observe the development of two-layer hydrates between 14.0 and $15.0 \AA$. For Arizona montmorillonite at a relative humidity of $8.9 \%$, we observe almost equal preference for the one- and two-layer hydrates at 12.4 and 14.6 $\AA$, respectively. For Wyoming montmorillonite at similar conditions, we see that the two-layer hydrate is still developing and a stable one-layer hydrate has a spacing of $12.4 \AA$. At a relative humidity of $67 \%$, the two-layer hydrates are the most favorable ones now, with basal spacings of 15.4 and $14.9 \AA$

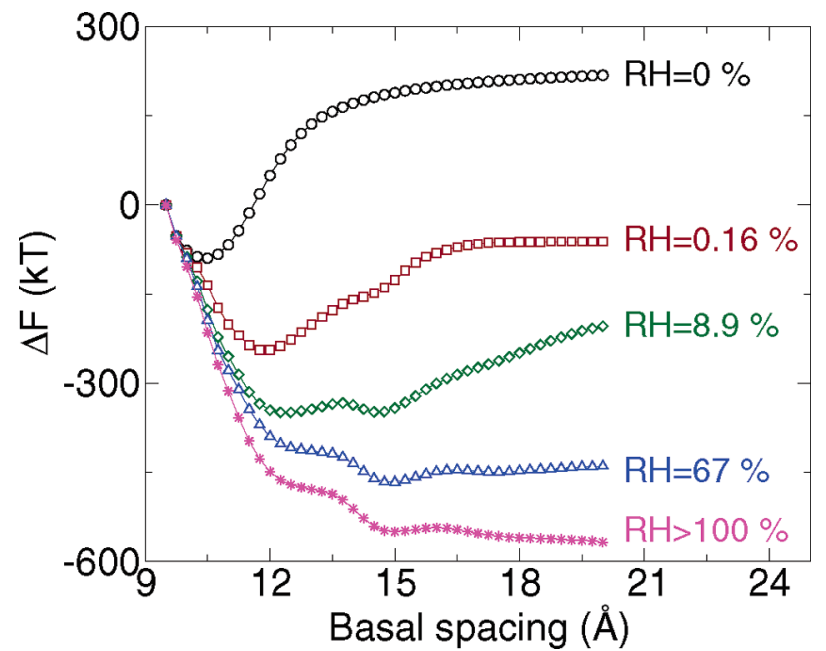

Figure 6. Free energy $(\Delta F)$ as a function of the basal spacing for Arizona Na-montmorillonite. Calculations are carried out using the TIP4P model for various values of the relative humidity (RH). Note that we did not correct the data for an external pressure at $\mathrm{RH}>100 \%$.

for Wyoming and Arizona, respectively. However, an energy barrier between the one- and two-layer hydrates of Wyoming montmorillonite prevents the swelling, whereas no such barrier is present for Arizona Na-montmorillonite. The differences between the swelling behaviors of these two types of clay are probably related to the higher water content in Arizona Namontmorillonite, induced by the higher number of cations and their positions. These positions are related to the charge substitutions in the clay. Tamura et al. ${ }^{43}$ suggested that the location of charge substitution sites causes different expansion behavior of clays, in agreement with our simulations. Arizona montmorillonite will reach a critical density for swelling in an earlier stage compared with Wyoming montmorillonite, under similar conditions. The start of three-layer hydrates formation at $67 \%$ relative humidity, with basal spacings between 17.0 and $18.0 \AA$, can also be observed. In case of a relative humidity higher than $100 \%$, both types of clay show macroscopic swelling, indicated by the negative slope of the free energy starting around $17.0 \AA$. Note that we did not correct for the external pressure due to the fact that a relative humidity higher than $100 \%$ implies a water density higher than the bulk liquid.

With increasing relative humidity (or water content), successive development of layered hydrates and their corresponding spacings are in agreement with experiments ${ }^{10,11,14,44}$ and simulations in different ensembles. ${ }^{15,16,18,19,29}$ Chipera et al. ${ }^{44}$ measured dehydrated states of Arizona Na-montmorillonite at $9.7 \AA$, onelayer hydrates at $12.3 \AA$, and two-layer hydrates at $15.3 \AA$. For Upton Na-montmorillonite, $\mathrm{Fu}$ et al. ${ }^{14}$ measured comparable spacings for these three stable states, while Cases et al. ${ }^{11}$ found similar results for Wyoming Na-montmorillonite.

The calculated spacings of Wyoming Na-montmorillonite by Boek et al. ${ }^{15}$ and Chávez-Páez et al. ${ }^{19}$ are in agreement with our simulations. Another study by Chávez-Páez et al. ${ }^{18}$ shows that stable spacings of Otay Na-montmorillonite (similar to our Arizona clay) are smaller than Wyoming Na-montmorillonite. Indicated by similar trends, these authors also showed that the swelling for both types of clay occurs at a similar number of water molecules in the interlayer space of the clay. The critical water density is therefore independent of the type of clay, which is supported by additional simulations for Wyoming and Otay Ca-montmorillonite. ${ }^{18}$ Compared to $\mathrm{Na}^{+}$as a counterion, these calculations show that the critical density depends on the type of counterion. Since calcium is present as a divalent ion, charge 
compensation is obtained by half the number of counterions for a given clay charge compared to charge compensation by monovalent ions.

To summarize, different types of clay swell at a similar critical water density for a certain counterion, but this critical density is reached at different humidity conditions. We already pointed out that the number of water molecules in the interlayer space for Arizona and Wyoming Na-montmorillonite depends on the relative humidity, induced by the number and the positions of the cations. We will further discuss the influence of the positions of the cations below.

III.A.3. Density Profiles. In the interlayer space of clay minerals we can distinguish so-called outer-sphere and innersphere cation-clay complexes. According to Sposito et al., ${ }^{45}$ inner-sphere complexes are formed when no water molecule is present between a cation and a surface functional group it binds to. On the other hand, outer-sphere complexes have at least one water molecule interposed between the cation and the surface. Cations that are not sorbed to the clay layers are present in the so-called diffuse-layer. Simulations by Greathouse and Sposito ${ }^{46}$ show outer-sphere complex formation exclusively for Lihectorite $(0.75 e$ octahedral charge per unit-cell) and solely inner-sphere complex formation for Li-beidellite $(0.75 e$ tetrahedral charge per unit-cell). In the case of Wyoming Limontmorillonite, which bears both octahedral and tetrahedral layer charge, they found both inner-sphere and outer-sphere complexes.

In Figure 7 we show density profiles of stable one-, two-, and three-layered hydrates for Wyoming and Arizona montmorillonite. The peaks corresponding to the oxygen atoms of the water molecules indicate that these are organized in one, two, and three layers in the interlayer space. The ion distribution in the one-layer hydrates of both clay minerals points to the formation of inner-sphere and outer-sphere complexes. Whereas in Arizona montmorillonite we only encounter outer-sphere complexes, the four cation peaks in the Wyoming clay indicate inner-sphere and outer-sphere complex formation, consistent with the $\mathrm{NP}_{z} \mathrm{~T}$ simulations by Boek et al. ${ }^{15}$ and Chávez-Páez et al. ${ }^{19}$ The inner-sphere complexes are formed with the cations that move close to the surface and bind to tetrahedral substitutions. These inner-sphere complexes remain in the two- and three-layered hydrates of Wyoming montmorillonite, but the other cations move to the diffuse-layer. Again, the structure of the two-layer hydrate is in agreement with those simulated by Boek et al. ${ }^{15}$ and Chávez-Páez et al. ${ }^{19}$ Two- and three-layer hydrates of Arizona montmorillonite only have cations in the diffuse-layer, at similar positions as in the case of Wyoming montmorillonite. These cations are located between the water layers (see Figure 7).

III.A.4. Dehydrated States. Figure 4-6 show that, independent of the type of clay mineral, we simulate the dehydrated state at a relative humidity of $0 \%$. If we introduce a few water molecules in the dehydrated state, the pressure increases dramatically and swelling occurs. Experimentally, the dehydrated state is observed from $0 \%$ to $20 \%$ relative humidity. ${ }^{44}$ In this humidity range, water molecules can adsorb on the outer surface of the clay minerals, but our simulations show that some water molecules can also adsorb in the interlayer at $0.16 \%$ and $8.9 \%$ relative humidity. Consequently, these water molecules induce swelling, and therefore we underestimate the transition between the dehydrated state and the one-layer hydrate. This underestimation follows the trend we mentioned above and is in agreement with other $\mathrm{NP}_{z} \mathrm{~T}^{18,19,32}$ and $\mu \mathrm{P}_{z} \mathrm{~T}^{29}$ simulations, showing rapid increase of the spacing after introducing a few water molecules.
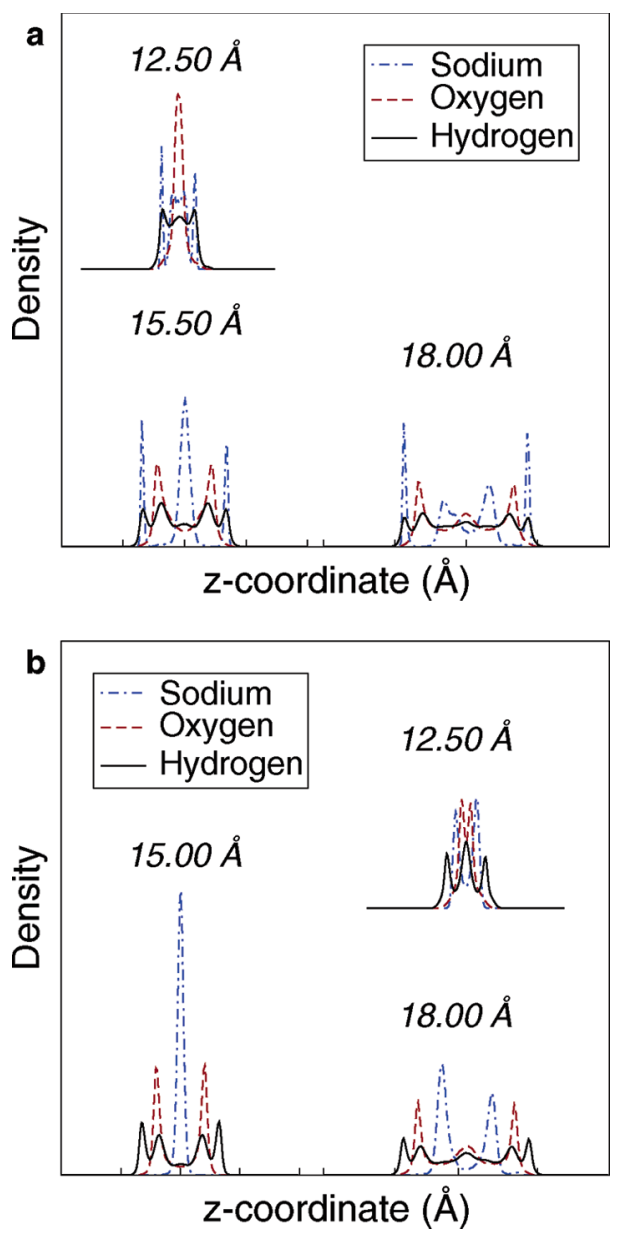

Figure 7. Density profiles of oxygen and hydrogen (TIP4P water) and sodium in Wyoming (a) and Arizona (b) Na-montmorillonite. We show the stable one-layer (12.50 $\mathrm{A})$, two-layer (15.50 and $15.00 \AA$ ), and three-layer $(18.00 \AA$ ) hydrates at a relative humidity of $8.9 \%, 67 \%$, and $>100 \%$, respectively.

The underestimation of the dehydrated state might also be caused by inaccurate description of the clay-clay interactions, something we will discuss below in more detail.

We already mentioned that our water adsorption isotherm at similar water chemical potential is in agreement with the one of Chávez-Páez et al. ${ }^{19}$ However, our pressure calculations are somewhat different, especially for the dehydrated state. The curve of $P_{z}$ as a function of the basal spacing by Chávez-Páez et al. ${ }^{19}$ shows an intersection with the external pressure (1 atm) followed by a minimum. Our pressure curve does not have such an intersection in the dehydrated state domain under similar relative humidity conditions, which is the reason we do not observe the dehydrated state. If we would integrate the pressure curve of Chávez-Páez et al., ${ }^{19}$ the corresponding free energy profile would show a preference for the dehydrated state with a high barrier for swelling to the one-layer hydrate. Thus, our simulations underestimate the dehydrated state, whereas ChávezPáez et al. ${ }^{19}$ overestimate its existence. However, according to our interpretation the $\mathrm{NP}_{z} \mathrm{~T}$ and $\mu \mathrm{VT}$ simulation results of Chávez-Páez et al. ${ }^{19}$ show different trends. For $N_{\text {water }}=16$, their constant pressure simulations predict a stable one-layer hydrate of approximately $11.90 \AA$, whereas their grand-canonical simulations predict that $N_{\text {water }}=16$ is reached at a spacing of approximately $11.25 \AA$, together with a negative pressure, pointing to shrinking.

Clay-clay interactions might explain the differences between experiments and our simulations. Skipper et al. ${ }^{22}$ already 


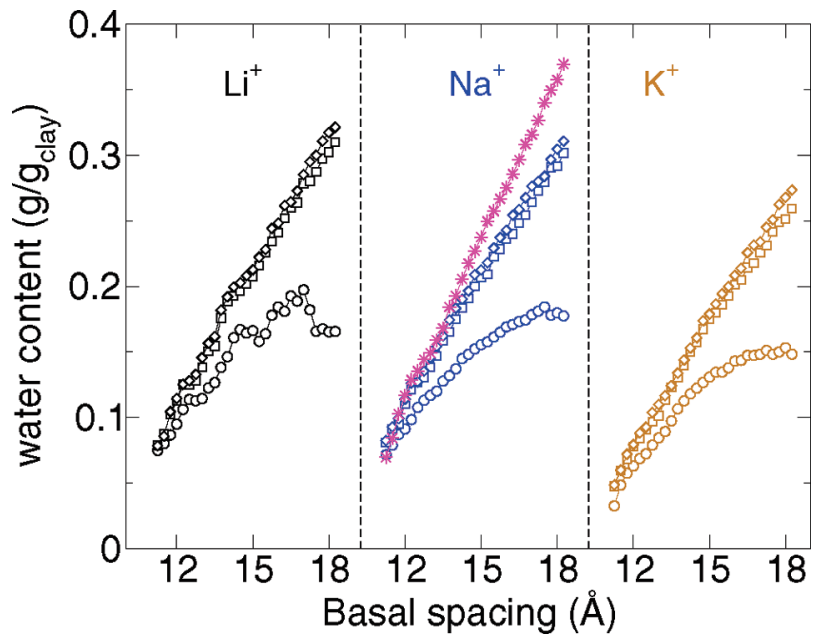

Figure 8. Water content as a function of the basal spacing for Arizona $\mathrm{Li}-$, Na-, and K-montmorillonite. Graphs correspond to a relative humidity of $1.4 \%$ (lower), $41 \%$ (middle), and $100 \%$ (upper). For the same clay mineral, the graph with asterisks (middle column) shows the water content calculated with the TIP4P model and the relative humidity $>100 \%$. We zoomed in on the one-, two-, and three-layer hydrates.

suggested that these interactions are not well described by the current models. We followed the approach of Boek et al. ${ }^{15}$ and represented the oxygen atoms of the clay surface by TIP4P (water) oxygen atoms. This water model, however, does not take into account separate van der Waals interactions between hydrogen atoms and between hydrogen and oxygen atoms, ${ }^{39}$ but these interactions are embedded in the potential describing the interaction between two oxygen atoms. In addition, the partial charges of water and clay oxygen atoms are also different, and in that case we might expect the same for their potentials. Similar to Boek et al., ${ }^{15}$ we did not take into account the van der Waals interactions between any other clay atoms. Therefore incomplete description of the clay-clay interactions may be the origin of the discrepancy between experiments and simulations.

III.B. Arizona Li-, Na-, and K-Montmorillonite with MCY Water. We carried out simulations with Arizona montmorillonite and three different cations $\left(\mathrm{Li}^{+}, \mathrm{Na}^{+}\right.$, and $\left.\mathrm{K}^{+}\right)$using the MCY water model and other interaction potentials from Park and Sposito. ${ }^{36}$ For all three cations, Figure 8 and Figure 9 show the water content and the free energy as a function of the basal spacing at dry $(1.4 \%)$, intermediate $(41 \%)$, and saturated $(100 \%)$ relative humidity, respectively. For comparison, we also included the water adsorption isotherm, calculated at $>100 \%$ relative humidity, using the TIP4P model and Arizona Na-montmorillonite in Figure 8. For the TIP4P model, we calculated that the water content at $\mathrm{RH}>100 \%$ is only slightly higher than at a relative humidity of $67 \%$ (not shown), similar to Wyoming Namontmorillonite (see Figure 3). Therefore, we can compare the water adsorption isotherm of MCY at $100 \% \mathrm{RH}$ with the one of TIP4P at RH > $100 \%$.

The water adsorption isotherms show an increase of the water content with increasing basal spacing, except for a low relative humidity $(\mathrm{RH}=1.4 \%)$. In this case, the water content remains constant at a certain basal spacing. We clearly see a cation effect on the water adsorption isotherms. Whereas $\mathrm{Li}$ - and $\mathrm{Na}-$ montmorillonite have comparable water content, this quantity is significantly lower for K-montmorillonite. We observe the successive formation of layered hydrates with increasing relative humidity (see Figure 9). The calculated spacings corresponding to the one-, two-, and three-layered hydrates are approximately

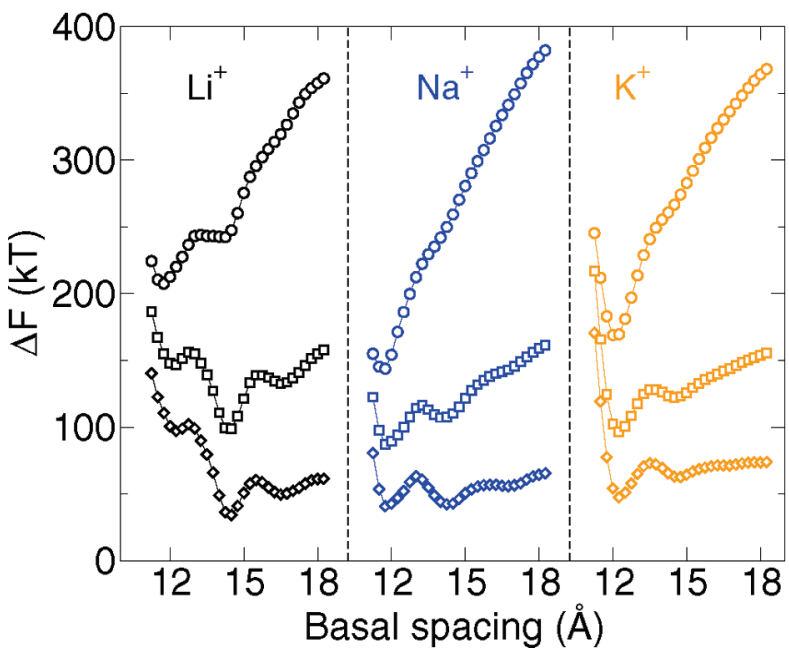

Figure 9. Free energy $(\Delta F)$ as a function of the basal spacing for Arizona $\mathrm{Li}-, \mathrm{Na}-$, and $\mathrm{K}$-montmorillonite. Graphs correspond to a relative humidity of $1.4 \%$ (upper), $41 \%$ (middle), and $100 \%$ (lower), respectively. We zoomed in on the one-, two-, and three-layer hydrates. Since we shifted the graphs for good comparison, only relative free energy differences should be compared. Figure 10 shows density profiles corresponding to stable layered hydrates shown in this graph.

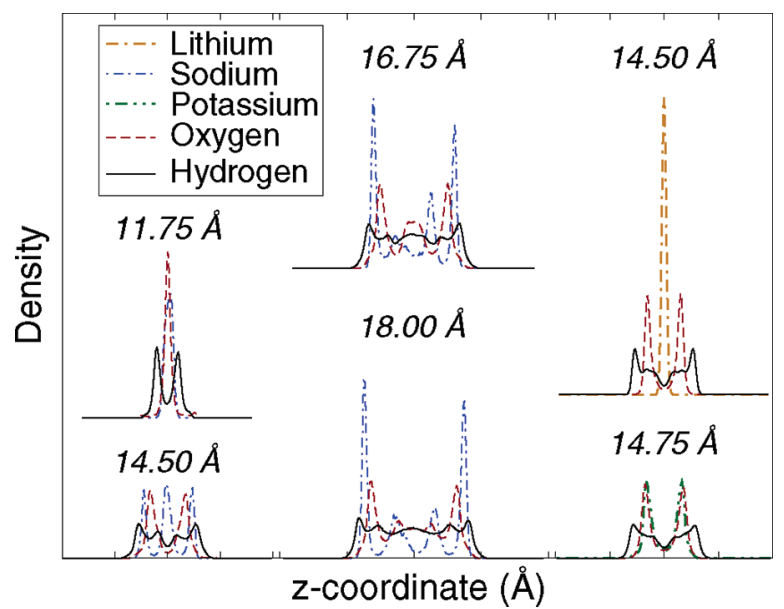

Figure 10. Arizona montmorillonite density profiles of layered hydrates, calculated with the MCY water model. Left and middle columns show sodium, upper right shows lithium, and lower right shows potassium. For better resolution, we increased the magnitude of the density profiles in the middle column by a factor of 1.75. All density profiles correspond to a relative humidity of $100 \%$ (see also Figure 9).

12.0, $14.5 \AA$, and $16.8 \AA$ respectively. The stability of the layered hydrates, indicated by the energy minima, depends on the type of cation.

Figure 10 shows two-layer hydrate density profiles of Arizona montmorillonite for the three cations, as well the one- and threelayer hydrates of Na-montmorillonite. We also included a density profile at $18.00 \AA$ to compare this with the three-layer hydrate simulated with TIP4P model. We observe that the localization of the cations in the two-layer hydrates depends on the type of cation. In general, the smaller the cation, the more affinity it shows for the diffuse-layer instead of forming a complex with the clay surface. The preference for the diffuselayer is probably related to the hydration energy. Smaller cations hydrate better than larger cations. We relate the two-layer hydrate interlayer structures for the three cations with the formation of the layered hydrates (Figure 9) and conclude that swelling is dependent on the distribution of the cations. The more cations leave the clay surface to the diffuse-layer, the easier swelling is. This finding agrees with the clay swelling mech- 
anism proposed by Hensen and Smit. ${ }^{29}$ Furthermore, it contributes to answering the question of why Arizona montmorillonite swells in an earlier stage than Wyoming montmorillonite, as discussed above. It was already mentioned that the tetrahedral charges of Wyoming clay minerals form inner-sphere complexes with cations.

For all three cations, we can compare our two-layer hydrate Arizona montmorillonite structures and spacings with those simulated for Wyoming montmorillonite by Chang et al. ${ }^{17,34,35}$ For Na-montmorillonite we observe outer-sphere complexes and ions in the diffuse-layer. In addition to these positions, Chang et al. ${ }^{35}$ found inner-sphere-complexed cations as well. Due to the absence of tetrahedral substitutions in the presently studied Arizona montmorillonite, we do not expect these complexes. With their $\mathrm{NP}_{z} \mathrm{~T}$ simulations, Chang et al. ${ }^{35}$ computed spacings of $12.08,15.28$, and $18.77 \AA$ and assigned these to be the one-, two-, and three-layer hydrates. Especially the spacing of the three-layer hydrate is significantly different from our spacing of approximately $16.8 \AA$. The three-layer hydrate density profiles of Chang et al. ${ }^{35}$ show the formation of four water layers instead of three. They explain that surface-complexed $\mathrm{Na}^{+}$has water molecules in its solvation shell, contributing to two major layers offset in the midplane. The other two layers of water molecules are associated with $\mathrm{Na}^{+}$in the midplane, which are part of a so-called diffuse ion-swarm. Based on our results, we would rather call their three-layer hydrate with four layers of water molecules a four-layer hydrate. The initial spacing of Chang et al. ${ }^{35}$ was $19.0 \AA$ for the three-layer hydrate. Probably, the simulation was trapped in a local minimum, corresponding to a four-layer hydrate.

The differences between the two-layer hydrate density profiles of Arizona Li-montmorillonite (our work) and Wyoming Limontmorillonite (Chang et al. ${ }^{17}$ ) are also explained by tetrahedral substitutions. We find that the $\mathrm{Li}^{+}$counterions are exclusively present in the diffuse-layer, whereas Chang et al. ${ }^{17}$ show a small portion of inner-sphere-complexed cations due to the tetrahedral substitutions. The computed spacings ${ }^{17}$ of the one-, two-, and three-layer hydrates are $12.27,15.06$, and $19.48 \AA$ respectively. Again, the spacing of the three-layer hydrate is significantly different from our spacing (approximately $16.8 \AA$ ) for the same reason as for Na-montmorillonite mentioned above. Note that with the MCY-TIP4P hybrid model, Chang et al. ${ }^{17}$ computed a spacing of $17.2 \AA$, which is in better agreement with our result.

Our density profiles for Arizona K-montmorillonite show the exclusive formation of outer-sphere complexes, whereas Chang et al. ${ }^{34}$ show the formation of outer- and inner-sphere complexes, the latter resulting from tetrahedral substitutions. In our simulations and those of Chang et al., ${ }^{34}$ the counterions only have small affinity for the diffuse-layer. Sposito et al. ${ }^{45}$ mention that potassium ions have less interaction with water, making the desolvation process facile, in agreement with our simulations. The computed spacings ${ }^{34}$ of the one-, two-, and three-layer hydrates are $12.46,16.30$, and $20.06 \AA$ respectively. The latter two are averaged over five and four different simulations, respectively. Chang et al. ${ }^{34}$ do not show density profiles of the water layers, but their calculated spacings of the two- and threelayer hydrate are significantly different from our calculated spacings, probably for the same reason as mentioned above for $\mathrm{Na}^{+}$and $\mathrm{Li}^{+}$as a counterion.

III.C. Comparison of the TIP4P and MCY Water Models. We already pointed out the ongoing discussion about the use of different water models. In the following we compare our results of the TIP4P model with those obtained using the MCY model. We recall that we compare these two models by the relative humidity instead of absolute values of the water chemical potential. Our calculated value of the TIP4P saturated water chemical potential shows an underestimation of the experimental value, whereas the MCY model overestimates this value (see section II.C.).

When we compare the water adsorption isotherms, we observe that the water content is almost equal at small spacings, even up to the one-layer hydrate (see Figure 8). However, the isotherms start diverging between 13.0 and $14.0 \AA$, indicating a clear difference between both water models. We expect such a difference, because with increasing spacing the system starts to approach bulk water and pressure oscillations will decay. ${ }^{41}$ We already pointed out that the liquid density of MCY water is approximately $75 \%$ of the TIP4P liquid density (see Figure 2).

Similar to our results with the TIP4P model, we clearly observe the successive formation of layered hydrates with increasing relative humidity for our simulations with the MCY model (see Figure 9). Our calculated spacings with the TIP4P model are in better agreement with experimental data than the spacings calculated with the MCY model. The difference in spacing of both models is supported by density profiles. Overall, our computed interlayer structures are different for both models. Compared with the TIP4P model, the smaller spacing for the MCY one-layer hydrate results in a different cation distribution. Our previous simulations ${ }^{20}$ with a larger spacing indicated a similar cation distribution compared with our results for TIP4P shown here. However, the difference between the average positions of the hydrogen atoms are more striking. In the case of the TIP4P model, three hydrogen peaks are present, whereas only two hydrogen peaks appear in the MCY case. We can explain this using the background of both models. The MCY model was created by ab initio calculations of two water molecules, whereas experimental data are the underlying source of the TIP4P potentials. As a consequence, TIP4P water molecules probably tend to reproduce the tetrahedral structure of water better. This tendency might be important for the development of the one-layer hydrate. In the literature, however, it has been argued that this behavior of TIP4P water molecules is less suitable than MCY water in constrained environments such as clay minerals. ${ }^{22}$

Differences in cation distribution become clearer when comparing the two-layer hydrates of Arizona Na-montmorillonite, computed with MCY and TIP4P. In the former case, the cations are in the diffuse-layer and form outer-sphere complexes with the clay layers. Our TIP4P simulations predict that cations are only present in the diffuse-layer. Apparently, the clay surface is more attractive for $\mathrm{Na}^{+}$counterions in our simulations with MCY than with our TIP4P simulations. Note that we showed inner-sphere complex formation for Wyoming-type clay simulated with the TIP4P model.

From our results we conclude that the MCY model is less suitable for predicting swelling clay minerals. The computed basal spacings, supported by density profiles, show that the MCY model underestimates the layer spacings.

III.D. Regular Patterns of One-Layer Hydrates. In the course of our simulations, we observed regular patterns of interlayer species in the one-layer hydrates of Arizona Li-, Naand K-montmorillonites at $12.0 \AA$, calculated with the MCY water model. The pattern requires that $N_{\text {water }} / N_{\text {cation }}$ is 2.0 , corresponding to 16 water molecules per interlayer and a water content of approximately $0.050 \mathrm{~g} / \mathrm{g}_{\text {clay }}$. Each water molecule is shared by two cations, and four water molecules surround each cation. Figure 11 shows a snapshot of the intermolecular 


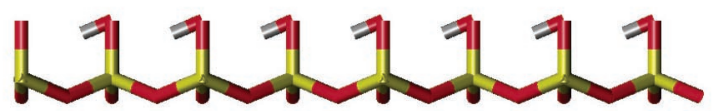

मำ

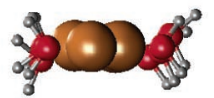

$\infty$

(a)
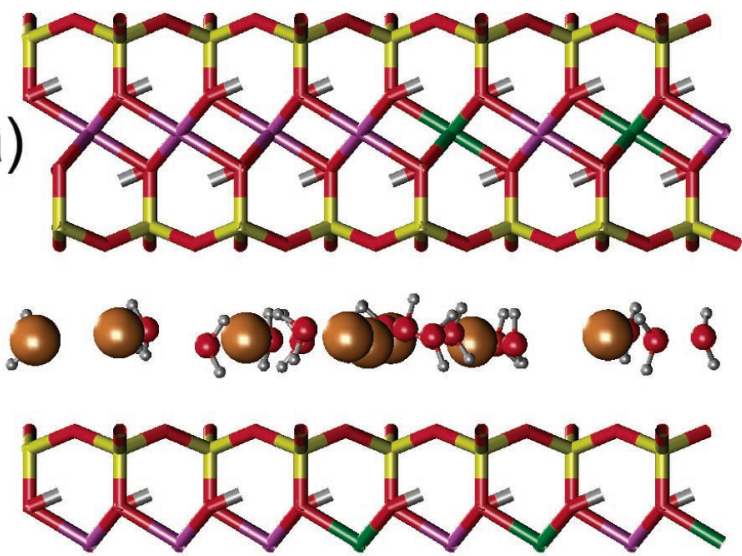

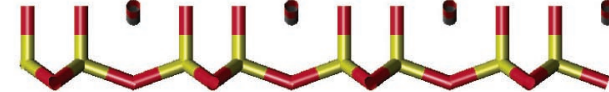

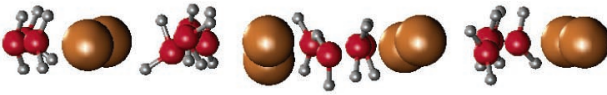

(b)
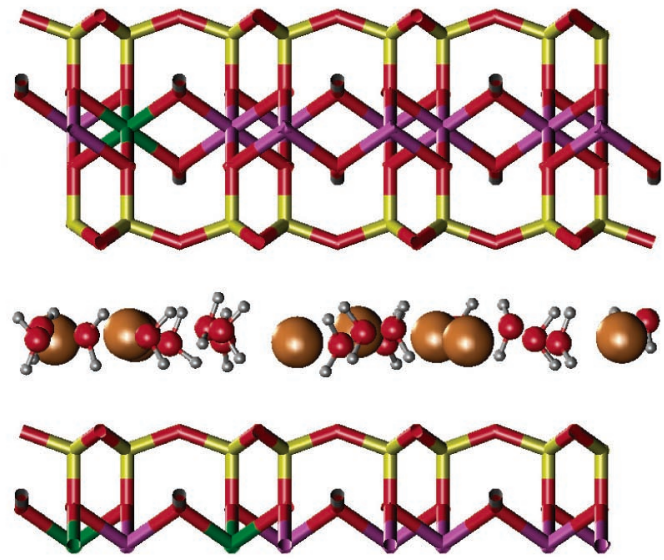

(c)

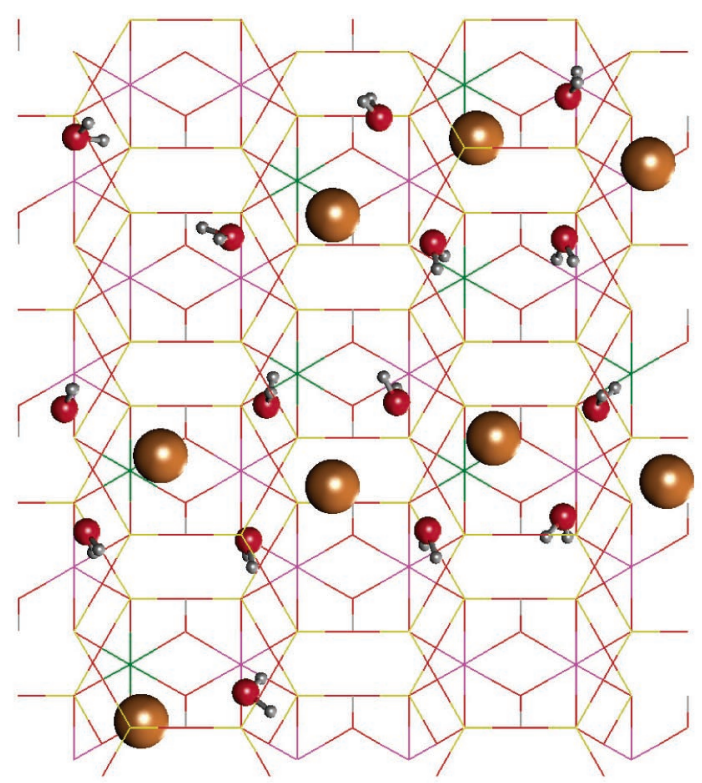

Figure 11. Ordered one-layer hydrates of Arizona K-montmorillonite at a relative humidity $\ll 1 \%$, calculated with the MCY water model. (a) Projection on the $x z$-plane, (b) projection on the $y z$-plane, and (c) projection on $x y$-plane of the upper interlayer in a and $\mathrm{b}$. The tubes represent the clay structure and the spheres the water molecules and cations. In the clay, $\mathrm{O}=$ red, $\mathrm{H}=$ silver, $\mathrm{Si}=$ yellow, $\mathrm{Al}=$ purple, and $\mathrm{Mg}=\mathrm{green} . \mathrm{For}$ water, $\mathrm{O}=$ red and $\mathrm{H}=$ silver, and $\mathrm{K}=$ orange.

structure of K-montmorillonite at $\mathrm{RH} \ll 1 \%$. The upper interlayer shows an ordered pattern, and apparently the randomly chosen substitution sites do not dominate their positions. The water molecules point one hydrogen atom toward the upper and one toward the lower clay sheet. This means that their dipole moments are parallel to the clay sheets. Oxygen atoms of the water molecules are pointed toward the cations. Four water molecules share one cation. Sutton et al. ${ }^{25}$ reported comparable results regarding water content and orientation of water molecules in $12.4 \AA$ Wyoming Cs-montmorillonite. They found an interlayer water content of $1.8 \mathrm{H}_{2} \mathrm{O}$ per $\mathrm{Cs}^{+}$, in agreement with experimental data $\left(1.6-1.8 \mathrm{H}_{2} \mathrm{O}\right.$ per $\left.\mathrm{Cs}^{+}\right)$. These data were corrected for possible adsorption on the exteriors of the clay. The water molecules in their simulation also have their dipole moments parallel to the clay sheets. Despite these similarities, Sutton et al. ${ }^{25}$ did not discuss these ordered structures, the main reason probably being the use of Wyoming montmorillonite. This type of clay bears tetrahedral charges, which might have a greater influence on the positions of the $\mathrm{Cs}^{+}$cations. Furthermore, Wyoming montmorillonite has less overall charge than Arizona montmorillonite. As a consequence, fewer cations are present in the interlayer.

By doing an additional simulation with a super cell that was doubled in the $x$ - and $y$-dimensions, we tested whether the ordered structures were an artifact of the relatively small simulation cell. Figure 12 shows a snapshot of this simulation ( $x y$-plane projection). Compared with Figure 11, similar patterns can be identified in Figure 12. Cations aggregate, and four water molecules share one cation. Dipole moments of the water molecules are again parallel to the clay sheets.

Our super cell simulations show that the ordering does not extend throughout the whole interlayer space. We should 


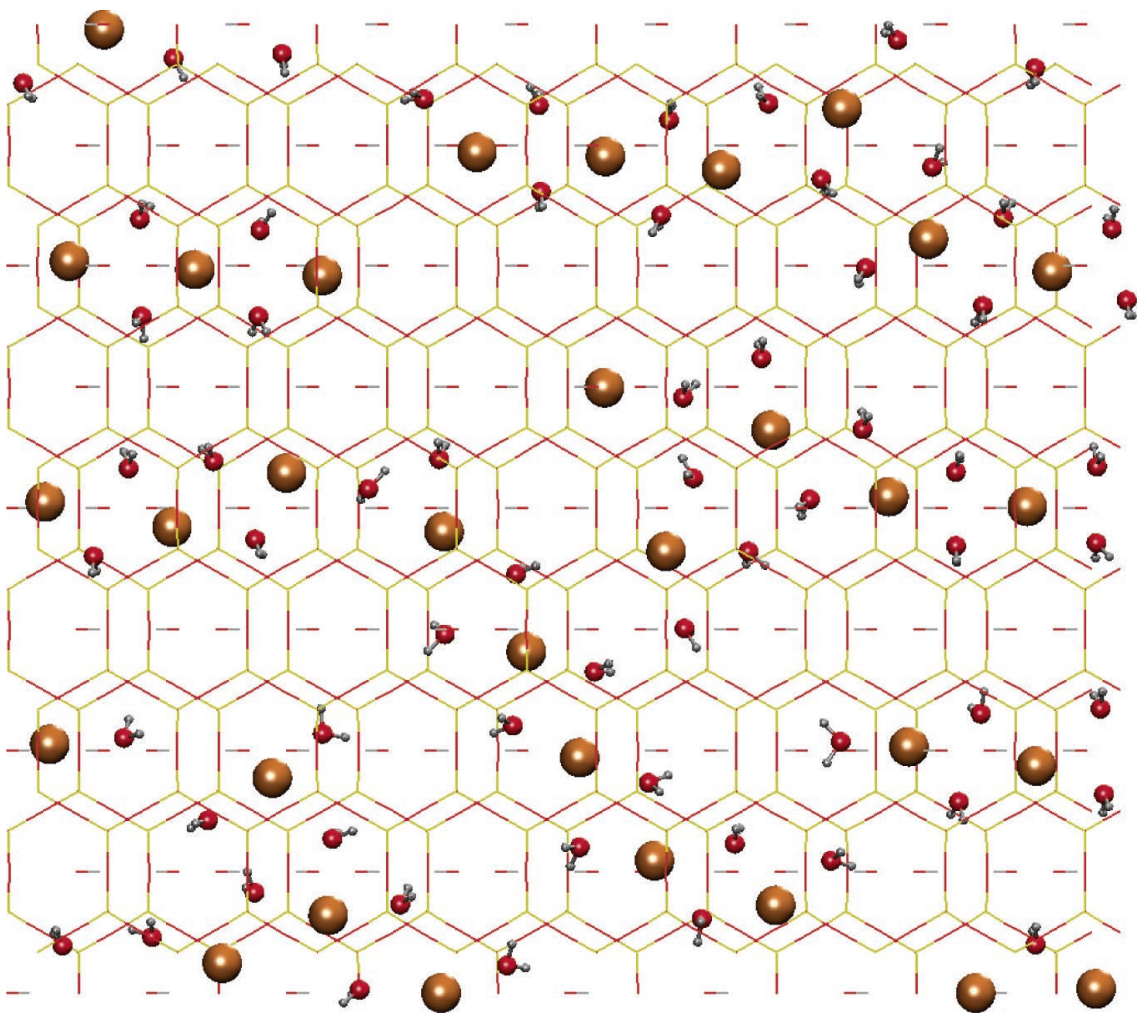

Figure 12. Projection on the $x y$-plane of ordered one-layer Arizona K-montmorillonite at a relative water humidity $\ll 1 \%$, calculated with the MCY water model. Simulation cell dimensions are: $x=42.24 \AA, y=36.56 \AA$, and the basal spacing is $12.00 \AA$. The tubes represent the clay structure and the spheres the water molecules and cations. In the clay, $\mathrm{O}=$ red, $\mathrm{H}=$ silver, $\mathrm{Si}=$ yellow, $\mathrm{Al}=$ purple, and $\mathrm{Mg}=$ green. For water, $\mathrm{O}=\operatorname{red}$ and $\mathrm{H}=$ silver, and $\mathrm{K}=$ orange.

mention that we studied Arizona montmorillonite bearing random substitutions in the octahedral layer. Ordering of these substitution sites might induce an ordering of the counterions as well. The ordered one-layer hydrates we discuss here require a very low relative humidity, and usually we observe dehydrated states at this condition. Perhaps there are ways to obtain such an ordered structure experimentally, but at this point we cannot think of any.

\section{Conclusions}

We have carried out grand-canonical molecular dynamics and Monte Carlo calculations on water and cations in rigid montmorillonite clay minerals. We studied several types of clay, water models, and cations. As a function of the basal spacing and with increasing relative humidity, we calculated water adsorption isotherms and the pressure normal to the clay sheets. We obtained the free energy by integrating the normal pressure term. With respect to all studied clay minerals, counterions, and water models, the general qualitative behavior is similar. A few characteristic details are summarized below.

At fixed low relative humidity and increasing basal spacing, the sorption of water molecules initially increases. At relative large basal spacing, the water density decreases and the water molecules are essentially only sorbed to clay-cation complexes. At fixed high relative humidity, the sorption process remains progressive with increasing basal spacing. The pressure normal to the clay sheet oscillates as a function of the basal spacing. Minima in the corresponding free energy curves indicate stable dehydrated states and stable layered hydrates.

Our simulations with several types of monovalent counterions show a difference in stability of the two-layer hydrate. Based on corresponding density profiles, we interpret that the evolution of stable states is related to positions of the cations in the interlayer space of the clay mineral. We showed that for different types of clays, the swelling occurs at different relative humidity. This is related to different numbers and/or positions of the cations. The basal spacings of one-layer hydrates, calculated with the TIP4P and MCY water models, show reasonable agreement with experimentally measured spacings. The MCY model underestimates the spacings of the two- and three-layer hydrates. Based on these results, we recommend the TIP4P model instead of the MCY model for simulating clay-water systems.

We simulated ordering of cations and water molecules in the one-layer hydrate of Arizona K-montmorillonite. We noted that possible experimental observation of such structures requires a low relative humidity and probably a modified clay structure regarding the substitution sites.

Acknowledgment. This work is supported in part by The Netherlands Research Council for Chemical Sciences (CW) through PIONIER. We thank Dr. P. G. Bolhuis, Dr. C. Laforge, and Dr. E. S. Boek for their contributions and helpful suggestions.

\section{References and Notes}

(1) Bleam, W. F. Rev. Geophys. 1993, 31, 51. 1960.

(2) Grim, R. E. Applied Clay Mineralogy; McGraw-Hill: New York,

(3) Karaborni, S.; Smit, B.; Heidug, W.; Urai, J.; Van Oort, E. Science 1995, 271, 1102

(4) Durand, C.; Forsans, T.; Ruffet, C.; Onaisi, A.; Audibert, A. Rev. Inst. Fr. Pet. 1995, 50, 187.

(5) Mooney, R. W.; Keenan, A. G.; Wood, L. A. J. Am. Chem. Soc. 1952, 74, 1367

(6) Mooney, R. W.; Keenan, A. G.; Wood, L. A. J. Am. Chem. Soc. 1952, 74, 1371.

(7) Farmer, V. C.; Russel, J. D. Trans. Faraday Soc. 1971, 67, 2737. 

$23,1$.

8) Suquet, H.; de la Calle, C.; Pezerat, H. Clays Clay Miner. 1975

(9) Kraehenbuehl, F.; Stoeckli, H. F.; Brunner, F.; Kahr, G.; MuellerVonmoos, M. Clay Miner. 1987, 22, 1.

(10) Brindley, G. W.; Brown, G. Crystal Structures of Clay Minerals and Their X-ray Identification; Mineralogical Society: London, 1980

(11) Cases, J. M.; Bérend, I.; Besson, G.; François, M.; Uriot, J.-P.; Thomas, F.; Poirier, J. E. Langmuir 1992, 8, 2730.

(12) Bérend, I.; Cases, J. M.; François, M.; Uriot, J.-P.; Michot, L.;

Masion, A.; Thomas, F. Clays Clay Miner. 1995, 43, 324.

(13) Schultz, L. G. Clays Clay Miner. 1969, 17, 115

(14) Fu, M. H.; Zhang, Z. Z.; Low, P. F. Clays Clay Miner. 1990, 38 485

(15) Boek, E. S.; Coveney, P. V.; Skipper, N. T. J. Am. Chem. Soc. 1995, 117, 12608

(16) Boek, E. S.; Coveney, P. V.; Skipper, N. T. Langmuir 1995, 11, 4629.

(17) Chang, F.-R. C.; Skipper, N. T.; Sposito, G. Langmuir 1997, 13, 2074.

(18) Chávez-Páez, M.; dePablo, L.; dePablo, J. J. J. Chem. Phys. 2001, $114,10948$.

(19) Chávez-Páez, M.; Van Workum, K.; dePablo, L.; dePablo, J. J. J. Chem. Phys. 2001, 114, 1405.

(20) Hensen, E. J. M.; Tambach, T. J.; Bliek, A.; Smit, B. J. Chem. Phys. 2001, 115, 3322

(21) Shroll, R. M.; Smith, D. E. J. Chem. Phys. 1999, 111, 9025.

(22) Skipper, N. T.; Chang, F.-R. C.; Sposito, G. Clays Clay Miner. 1995, 43, 285

(23) Skipper, N. T.; Refson, K.; McConnell, J. D. C. J. Chem. Phys. 1991, 94, 7434 .

(24) Skipper, N. T.; Sposito, G.; Chang, F.-R. C. Clays Clay Miner. 1995, 43, 294

(25) Sutton, R.; Sposito, G. J. Colloid Interface Sci. 2001, 237, 174

(26) Delville, A. J. Phys. Chem. 1993, 97, 9703.

(27) Delville, A. J. Phys. Chem. 1995, 99, 2033.
(28) Delville, A.; Sokolowski, S. J. Phys. Chem. 1993, 97, 6261.

(29) Hensen, E. J. M.; Smit, B. J. Phys. Chem. B 2002, 106, 12664

(30) Boek, E. S.; Sprik, M. J. Phys. Chem. B 2003, 107, 3251.

(31) Young, D. A.; Smith, D. E. J. Phys. Chem. B 2000, 104, 9163.

(32) Smith, D. E. Langmuir 1998, 14, 5959.

(33) Marry, V.; Turq, P. J. Phys. Chem. B 2003, 107, 1832.

(34) Chang, F.-R. C.; Skipper, N. T.; Sposito, G. Langmuir 1998, 14 1201

(35) Chang, F.-R. C.; Skipper, N. T.; Sposito, G. Langmuir 1995, 11, 2734.

(36) Park, S.-H.; Sposito, G. J. Phys. Chem. B 2000, 104, 4642.

(37) Frenkel, D.; Smit, B. Understanding Molecular Simulation, 2nd ed.; Academic Press: San Diego, CA, 2002.

(38) Matsuoka, O.; Clementi, E.; Yoshimine, M. J. Chem. Phys. 1976, 64, 1351 .

(39) Jorgensen, W. L.; Chandrasekhar, J.; Madura, J.; Impey, R. W.; Klein, M. J. Chem. Phys. 1983, 79, 926.

(40) Aspen Plus, version 11.1; Aspen Technology Inc., Polymer Technology Division: Cambridge, MA, 2001.

(41) Israelachvili, J. N. Surf. Sci. Rep. 1992, 14, 109.

(42) De Siqueira, A. V. C.; Skipper, N. T.; Coveney, P. V.; Boek, E. S. Mol. Phys. 1997, 92, 1.

(43) Tamura, K.; Yamada, H.; Nakazawa, H. Clays Clay Miner. 2000, 48,400

(44) Chipera, S. J.; Carey, J. W.; Bish, D. L. Controlled-Humidity XRD Analyses: Application to the Study of Smectite Expansion/Contraction. In Advances in X-ray Analysis; Gilfrich, J. V., Jenkins, R., Snyder, R. L., Eds.; Plenum Press: New York, 1997; Vol. 39, p 713.

(45) Sposito, G.; Skipper, N. T.; Sutton, R.; Park, S.-H.; Soper, A. K.; Greathouse, J. A. Proc. Natl. Acad. Sci. U.S.A. 1999, 96, 3358.

(46) Greathouse, J. A.; Sposito, G. J. Phys. Chem. B 1998, 102, 2406.

(47) Kell, G. S. Thermodynamic and Transport Properties of Fluid Water. In Water, A Comprehensive Treatise; Franks, F., Ed.; Plenum Press: New York-London, 1972; Vol. 1, p 363. 